\title{
CHEMOSPHERE
}

\section{Degradation of dyes in aqueous solutions by the Fenton process}

\author{
Xiang-Rong $\mathrm{Xu}^{\text {a }}$, Hua-Bin $\mathrm{Li}^{\mathrm{a}}$, Wen-Hua Wang ${ }^{\mathrm{b}}$, Ji-Dong $\mathrm{Gu}^{\mathrm{a}, \mathrm{c}, *}$ \\ a Laboratory of Environmental Toxicology, Department of Ecology \& Biodiversity, The University of Hong Kong, \\ Pokfulam Road, Hong Kong SAR, People's Republic of China \\ b State Key Laboratory of Environmental Aquatic Chemistry, Research Center for Eco-Environmental Sciences, \\ Chinese Academy of Sciences, Beijing 100085, People's Republic of China \\ c The Swire Institute of Marine Science, The University of Hong Kong, Shek O, Cape d'Aguilar, \\ Hong Kong SAR, People's Republic of China
}

Received 24 November 2003; received in revised form 7 June 2004; accepted 13 July 2004

\begin{abstract}
Degradation of 20 different dyes in aqueous solutions by the Fenton process was performed. These dyes include 6 types: acidic, reactive, direct, cationic, disperse and vat dyes. The former four types of dyes were decolorized and their TOC values were decreased greatly, while the color and TOC removals of the latter two types were lower. The catalytic activities of four metal ions on the degradation efficiencies of Vat Blue BO, which was chosen as a model dye because of its lowest color and TOC removals, were compared in the dark and under the ultraviolet light irradiation. The catalytic ability of different metals was $\mathrm{Fe}^{2+}>\mathrm{Cu}^{2+}>\mathrm{Mn}^{2+}>\mathrm{Ag}^{+}$in the dark, and the same sequence was obtained under irradiation condition with greater degradation efficiency. Furthermore, the efficiencies of three oxidation processes, including $\mathrm{H}_{2} \mathrm{O}_{2} / \mathrm{UV}, \mathrm{Fe}^{2+} / \mathrm{H}_{2} \mathrm{O}_{2}$ and $\mathrm{Fe}^{2+} / \mathrm{H}_{2} \mathrm{O}_{2} / \mathrm{UV}$ were compared. The results showed that the oxidation by $\mathrm{Fe}^{2+} / \mathrm{H}_{2} \mathrm{O}_{2} / \mathrm{UV}$ was the strongest, and even greater than the arithmetic sum of the other two processes, which suggests the synergistic effect of ultraviolet and ferrous ions on the degradation reaction.
\end{abstract}

(c) 2004 Elsevier Ltd. All rights reserved.

Keywords: Textile; Wastewater; Treatment; Hydrogen peroxide; Oxidation

\section{Introduction}

The worldwide annual production of the dyestuffs amounts to more than $7 \times 10^{5} t$ (Spadaro et al., 1994).

\footnotetext{
${ }^{*}$ Corresponding author. Address: Laboratory of Environmental Toxicology, Department of Ecology \& Biodiversity, The University of Hong Kong, Pokfulam Road, Hong Kong SAR, People's Republic of China. Tel.: +852 2299 0605; fax: +852 25176082.

E-mail address: jdgu@hkucc.hku.hk (J.-D. Gu).
}

There are many kinds of dyes on the market for various applications. In view of their chemical structures, dyes can be characterized as an azo dye, triaryl methane dye, anthraquinone dye, heterocyclic dye and phthalocyanine dye. Dyes can also be characterized according to their application method into vat dye, reactive dye, direct dye, acidic dye, disperse dye and cationic dye. Effluents from the textile industry commonly contain high concentrations of organic and inorganic chemicals and are characterized by very high COD and TOC values as well as strong color (Kurbus et al., 2003). Dye 
wastewater discharged from the textile industry can be extremely damaging to the environment if improperly disposed. The removal of dyes from industrial effluents is an area of research receiving increasing attention as government legislation on the release of contaminated effluent is becoming increasingly stringent.

Biological treatment of dye-containing wastewater is considered unsatisfactory because of the low efficiency and low reaction rate of the treatment. Consequently, dye wastewater is usually treated using physical and chemical methods (Chang et al., 2003). Flocculation and activated carbon adsorption have been used to treat dye-containing wastewater. However, sludge generation and adsorbent regeneration are the principal weakness of these processes (Slokar and Majcen Le Marechal, 1998). The Fenton process that uses $\mathrm{Fe}^{2+}$ to react with $\mathrm{H}_{2} \mathrm{O}_{2}$ to generate $\mathrm{OH}$ with powerful oxidizing ability, one of the advanced oxidation processes (AOPs), has been proposed for the degradation of organic pollutants (Chen and Pignatello, 1997; Benitez et al., 2001; Huang et al., 2002), including some dye pollutants (Kang et al., 2002; Feng et al., 2003; Swaminathan et al., 2003).

In this paper, degradation of 20 different types of dyes in aqueous solutions by the Fenton process was performed. In order to improve the degradation efficiency, catalytic activities of four metal ions on the degradation of Vat Blue BO were compared in the dark and under the UV light irradiation. Furthermore, the efficiencies of three oxidation processes, including $\mathrm{H}_{2} \mathrm{O}_{2} / \mathrm{UV}, \mathrm{H}_{2} \mathrm{O}_{2} / \mathrm{Fe}^{2+}$ and $\mathrm{H}_{2} \mathrm{O}_{2} / \mathrm{Fe}^{2+} / \mathrm{UV}$ were compared.

\section{Materials and methods}

\subsection{Materials}

The 20 dyes tested were Acidic Red B, Acidic Red G; Reactive Brilliant Red K-2BP, Reactive Brilliant Red K2G, Reactive Yellow KD-3G; Direct Fast Black GF, Direct Fast Turquoise Blue GL, Direct Fast Red F3B, Direct Yellow RL; Cationic Pink FG, Cationic Red XGRL, Cationic Black X-2RL, Cationic Yellow X-2GL; Disperse Red B; Disperse Violet HFRL; Disperse Brilliant Yellow 5GR; Vat Blue BO; Vat Direct Black RB; Vat Dark Blue VB and Vat Brilliant Violet RR. They were all purchased from the Eighth Dyestuff Factory in Shanghai. Copper sulfate, ferrous sulfate, manganese sulfate and silver nitrate were purchased from Beijing Chemical Reagent Factory. Distilled de-ionized water was used for all solutions and dilution. $\mathrm{H}_{2} \mathrm{O}_{2}(30 \%)$ and other reagents were obtained from Beijing Chemical Reagent Industrial Company. These chemicals were analytical grade.

\subsection{Experimental procedure}

The degradation of 20 dyes was carried out in graduated and plugged test tubes. Reaction mixtures were obtained by taking an appropriate amount of dye stock solution, adding ferrous ion, and adjusting $\mathrm{pH}$ value to 3 with $0.1 \mathrm{~N} \mathrm{H}_{2} \mathrm{SO}_{4}$ or $\mathrm{NaOH}$ solution. The final volume of the reaction mixture was $50 \mathrm{ml}$. The reaction was initiated by adding $\mathrm{H}_{2} \mathrm{O}_{2}$ and was terminated instantly by adding $0.5 \mathrm{ml}$ of $1 \mathrm{~N} \mathrm{Na}_{2} \mathrm{~S}_{2} \mathrm{O}_{3}$ solution to the reaction mixtures.

During the photo-Fenton $\left(\mathrm{Fe}^{2+} / \mathrm{H}_{2} \mathrm{O}_{2} / \mathrm{UV}\right)$ experiments, degradation of the dye in solution was carried out in a one litre cylindrical glass photo-reactor. A Hanovia model $25 \mathrm{~W}$ low pressure mercury lamp as a light source was located at center of the reactor. The spectral output of the lamp at $254 \mathrm{~nm}$ wavelength at the surface of the quartz well was $4.50 \mathrm{~mW} \mathrm{~cm}^{-2}$.

The optimized conditions had been obtained for the Fenton process in the previous work (Xu et al., 1999). Therefore, the concentrations of $\mathrm{Fe}^{2+}$ and $\mathrm{H}_{2} \mathrm{O}_{2}$ were 5 and $50 \mathrm{mM}$ and $\mathrm{pH}$ value was 3 , respectively. The concentration of dye solutions was $150 \mathrm{mgl}^{-1}$ in this experiment. The samples were withdrawn at regular time intervals and were filtered with Millipore membrane $(0.45 \mu \mathrm{m})$ before analysis.

The experiment was conducted three separate times, and each individual assay was conducted in duplicate. The mean values were presented together with vertical error bars indicating the standard deviations of the three experiments in the figures.

\subsection{Analytical methods}

A TOC analyzer (TOC-500, Shimadzu, Japan) was used to measure the concentration of organic carbon in aqueous solutions. The color of solution was analyzed using a Du-650 spectrophotometer (Du-650, Beckman, USA). Each dye solution was scanned from 300 to $800 \mathrm{~nm}$ and its maximum absorbance was determined. The color removal was based on the change of the maximum absorbance.

\section{Results and discussion}

\subsection{Degradation of 20 dye solutions by the Fenton process}

The Fenton process employs a mixture of $\mathrm{H}_{2} \mathrm{O}_{2}$ and $\mathrm{Fe}^{2+}$ under acidic $\mathrm{pH}$ conditions, which can generate great amount of $\mathrm{OH}$ with powerful oxidizing ability. 'OH may react with organics (Walling, 1975; Spacek et al., 1995):

Degradation of 20 commercial dyestuffs by the Fenton process was investigated. These dyes include 6 types: acidic, reactive, direct, cationic, disperse and vat dyes 
and their chemical structures include azo, triaryl methane, anthraquinone, heterocyclic and phthalocyanine. The chemical structures of 6 representative dyes, one per type, are shown in Fig. 1. The degradation results of dyes by the Fenton process are summarized in Table 1. The color removals of acidic, reactive, direct and cationic dyes were between $87 \%$ and $100 \%$, and the TOC removals were between $56 \%$ and $79 \%$. For disperse and vat dyes, the color and TOC removals were $30 \%-$ $56 \%$ and $21 \%-34 \%$, respectively suggesting that the molecules of disperse and vat dyes were more difficult to be destroyed by the Fenton process. The color removal was easier than the TOC removal indicating that the chromophoric groups were destroyed during the degradation of dyes, and were partly mineralized to $\mathrm{CO}_{2}$ and $\mathrm{H}_{2} \mathrm{O}$. Although the chromophoric structures of the dye molecules are destroyed by hydroxyl radicals, some colorless degradation intermediates are formed in solution during the reaction. In most cases, adjacent aromatic ring struc- ture is one of the intermediates (Kang et al., 1999). In addition, $\mathrm{pH}$ value of the solution decreased a little (about $0.1 \mathrm{pH}$ unit) during the decomposition of dyes by the Fenton process.

Among all dyes tested, the color and TOC removals of Vat Blue BO were lowest. Therefore Vat Blue BO was chosen in the following experiments to compare the catalytic activity of four metal ions and the degradation efficiency of three oxidation processes.

\subsection{Comparison of the catalytic activity of four metal ions}

In order to improve degradation efficiency, the catalytic activity of several metal ions was compared. The catalysts used in this study were $\mathrm{Fe}^{2+}, \mathrm{Cu}^{2+}$ and $\mathrm{Mn}^{2+}$. The selection of metal is based on the fact that transition metals, particularly those possess two or more valency states between which there is a suitable oxidation-reduction potential, can react with $\mathrm{H}_{2} \mathrm{O}_{2}$ to produce $\mathrm{OH}$.<smiles>O=[N+]([O-])c1cc(N=Nc2ccc(S(=O)(=O)O)c3ccccc23)c(O)c2ccccc12</smiles>

Acidic Red B<smiles>CS(=O)(=O)c1ccccc1N=Nc1c([N+](=O)[O-])cc2c(S(=O)(=O)O[Na])ccc(Nc3nc(Cl)nc(Nc4ccc(S(=O)(=O)O[Na])cc4)n3)c2c1O</smiles>

Reactive Brilliant Red K-2G

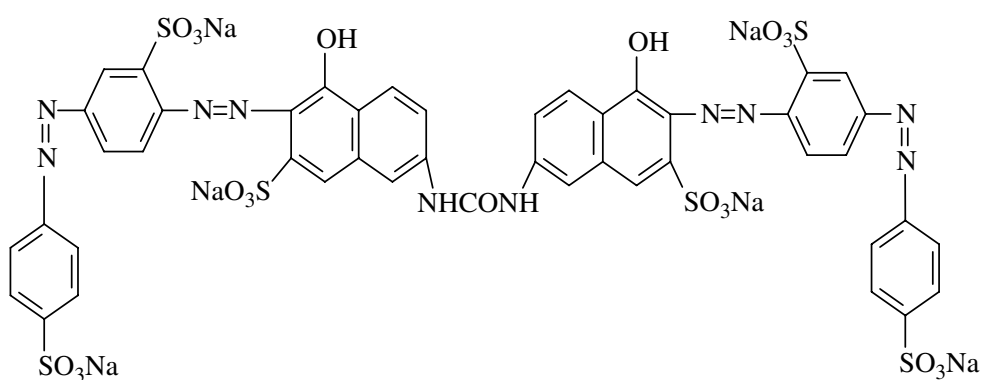

Direct Fast Red F3B<smiles>Nc1c(Oc2ccccc2)c(Oc2ccccc2)c(N)c2c1C(=O)c1ccccc1C2=O</smiles>

Disperse Violet HFRL<smiles>CN(CCCl)c1ccc(C=CC2=Nc3ccccc3C2(C)C)cc1</smiles>

Cationic Pink FG

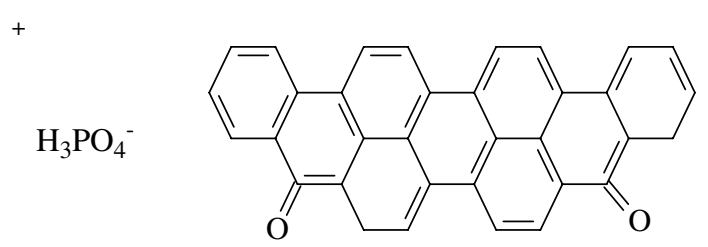

Vat Blue BO

Fig. 1. Chemical structures of 6 representative dyes. 
Table 1

The removals of color and TOC of 20 dyes used $^{\mathrm{a}}$

\begin{tabular}{llll}
\hline Dye & $\begin{array}{l}\lambda_{\max } \\
(\mathrm{nm})^{\mathrm{b}}\end{array}$ & $\begin{array}{l}\text { Color } \\
\text { removal (\%) }\end{array}$ & $\begin{array}{l}\text { TOC } \\
\text { removal (\%) }\end{array}$ \\
\hline Acidic Red B & 530 & $100 \pm 1$ & $67 \pm 3$ \\
Acidic Red G & 530 & $100 \pm 1$ & $62 \pm 1$ \\
Reactive Brilliant & 530 & $98 \pm 2$ & $76 \pm 4$ \\
Red K-2BP & & & \\
Reactive Brilliant & 530 & $100 \pm 1$ & $72 \pm 3$ \\
Red K-2G & & & \\
Reactive Yellow KD-3G & 420 & $96 \pm 2$ & $79 \pm 2$ \\
Direct Fast Black GF & 580 & $90 \pm 3$ & $66 \pm 3$ \\
Direct Fast Turquoise & 620 & $92 \pm 1$ & $74 \pm 4$ \\
Blue GL & & & \\
Direct Fast Red F3B & 530 & $87 \pm 2$ & $72 \pm 2$ \\
Direct Yellow RL & 420 & $91 \pm 4$ & $78 \pm 1$ \\
Cationic Pink FG & 540 & $96 \pm 2$ & $61 \pm 3$ \\
Cationic Red X-GRL & 550 & $98 \pm 1$ & $68 \pm 2$ \\
Cationic Black X-2RL & 580 & $92 \pm 3$ & $60 \pm 3$ \\
Cationic Yellow X-2GL & 470 & $94 \pm 1$ & $56 \pm 1$ \\
Disperse Red B & 520 & $56 \pm 2$ & $34 \pm 4$ \\
Disperse Violet HFRL & 640 & $47 \pm 3$ & $26 \pm 2$ \\
Disperse Brilliant & 420 & $41 \pm 2$ & $30 \pm 3$ \\
Yellow 5GR & & & \\
Vat Blue BO & 620 & $30 \pm 1$ & $21 \pm 1$ \\
Vat Brilliant Violet RR & 640 & $46 \pm 2$ & $27 \pm 2$ \\
Vat Direct Black RB & 580 & $37 \pm 1$ & $30 \pm 3$ \\
Vat Dark Blue VB & 630 & $39 \pm 3$ & $28 \pm 2$ \\
\hline \multicolumn{2}{c}{ a Reaction time } & & \\
\hline
\end{tabular}

${ }^{\mathrm{a}}$ Reaction time $=120 \mathrm{~min}, \mathrm{pH}=3$, Temperature $=20 \pm 1{ }^{\circ} \mathrm{C}$.

b $\lambda_{\text {max }}=$ wavelength of the maximum absorbance.

In addition, these transition metals are easily obtainable, inexpensive, and relatively low in toxicity. Furthermore, $\mathrm{Ag}^{+}$was also chosen to test its catalytic activity. Vat Blue $\mathrm{BO}$ was used as a model dye. The results of the color and TOC removals are shown in Fig. 2. Without addition of metal ions, both color and TOC removals were very low, indicating that Vat Blue BO was difficult to be oxidized by $\mathrm{H}_{2} \mathrm{O}_{2}$. It can be found that when catalysts were added into the reaction mixture, both color and TOC removals of Vat Blue $\mathrm{BO}$ were obviously enhanced. Metal ions can catalyze $\mathrm{H}_{2} \mathrm{O}_{2}$ to produce ${ }^{\circ} \mathrm{OH}$ with strong oxidizing ability. Hydrogen peroxide with an oxidation potential of $1.77 \mathrm{~V}$ has a less oxidizing power than hydroxyl radicals $(2.80 \mathrm{~V})$. The catalytic activity of $\mathrm{Mn}^{2+}$ was comparable with $\mathrm{Fe}^{2+}$ initially but gradually deviated from $\mathrm{Fe}^{2+} \cdot \mathrm{Cu}^{2+}$ showed a good catalytic ability during the degradation of Vat Blue BO although at the beginning of the degradation, its catalytic activity was comparatively lower than $\mathrm{Fe}^{2+}$ and $\mathrm{Mn}^{2+}$. At the end of the degradation, its catalytic activity was almost equal to that of $\mathrm{Fe}^{2+}$. $\mathrm{Ag}^{+}$was the least effective of the four tested metal ions. Catalytic activity of metal ions was found to be in the following sequence: $\mathrm{Fe}^{2+}>\mathrm{Cu}^{2+}>\mathrm{Mn}^{2+}>\mathrm{Ag}^{+}$.

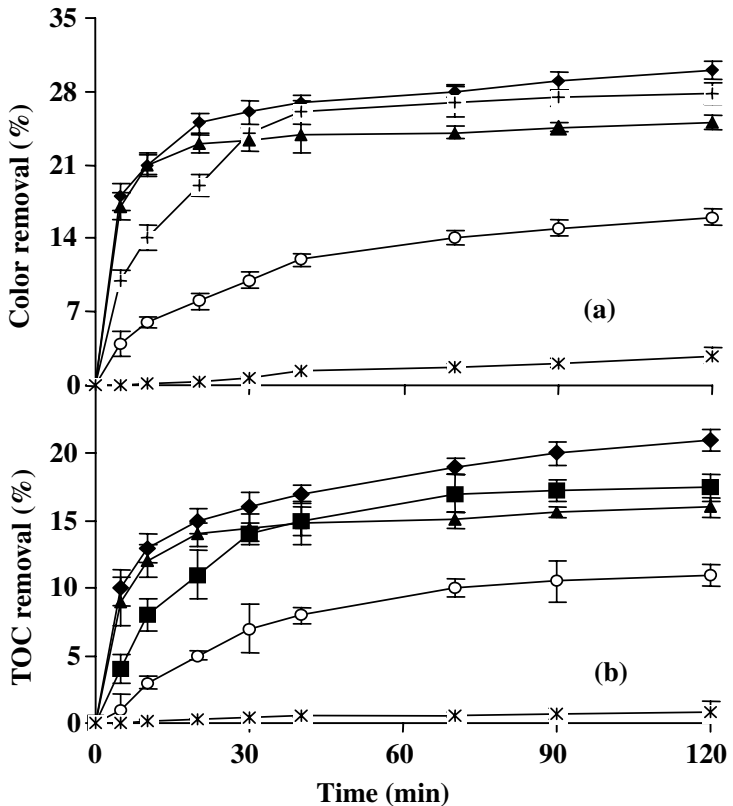

Fig. 2. Effect of four metal ions on the color (a) and TOC (b) removals of Vat Blue BO. [Vat Blue $\mathrm{BO}]=150 \mathrm{mgl}^{-1}$, [metal ions $]=5 \mathrm{mM},\left[\mathrm{H}_{2} \mathrm{O}_{2}\right]=50 \mathrm{mM}, \mathrm{pH}=3$. $(\diamond): \mathrm{Fe}^{2+} ;(+): \mathrm{Cu}^{2+}$; (४): $\mathrm{Mn}^{2+} ;(\mathrm{O}): \mathrm{Ag}^{+} ;($( ) : no metal.

\subsection{Comparison of the catalytic activity of four metal ions under UV light irradiation}

The oxidation of Vat Blue BO by the above mentioned metal ions and $\mathrm{H}_{2} \mathrm{O}_{2}$ was carried out under the UV light irradiation. The results are presented in Fig. 3. Removals of color and TOC were obviously enhanced under the UV light irradiation compared with results without irradiation. Without metal ions but with UV light, color and TOC removals were $26 \%$ and $15 \%$, respectively after $120 \mathrm{~min}$ of reaction. It indicated that degradation of Vat Blue BO was sensitized by the presence of UV light due to the favorable adsorption spectrum of $\mathrm{H}_{2} \mathrm{O}_{2}$. The direct photolysis of $\mathrm{H}_{2} \mathrm{O}_{2}$, requiring $\lambda<360 \mathrm{~nm}$, generates ${ }^{\circ} \mathrm{OH}$. ${ }^{\circ} \mathrm{OH}$ is known to react with organic chemicals by $\mathrm{H}$-abstraction from alkyl or hydroxyl groups (Walling, 1975) or by an electron transfer process (Bossmann et al., 1998). In the presence of $\mathrm{Fe}^{2+}, \mathrm{H}_{2} \mathrm{O}_{2}$ and UV light, the best color and TOC removals were obtained. Up to $64 \%$ of color and $45 \%$ of TOC of Vat Blue BO were removed after $120 \mathrm{~min}$.

Under the irradiation of UV light, the same sequence of the catalytic activity of the metal ions was obtained. The sequence of catalytic ability for metal ions alone and metal ions assisted by UV light was $\mathrm{Fe}^{2+}$ / $\mathrm{UV}>\mathrm{Cu}^{2+} / \mathrm{UV}>\mathrm{Mn}^{2+} / \mathrm{UV}>\mathrm{Ag}^{+} / \mathrm{UV}>\mathrm{Fe}^{2+}>\mathrm{Cu}^{2+}>$ $\mathrm{Mn}^{2+}>\mathrm{Ag}^{+}$. 


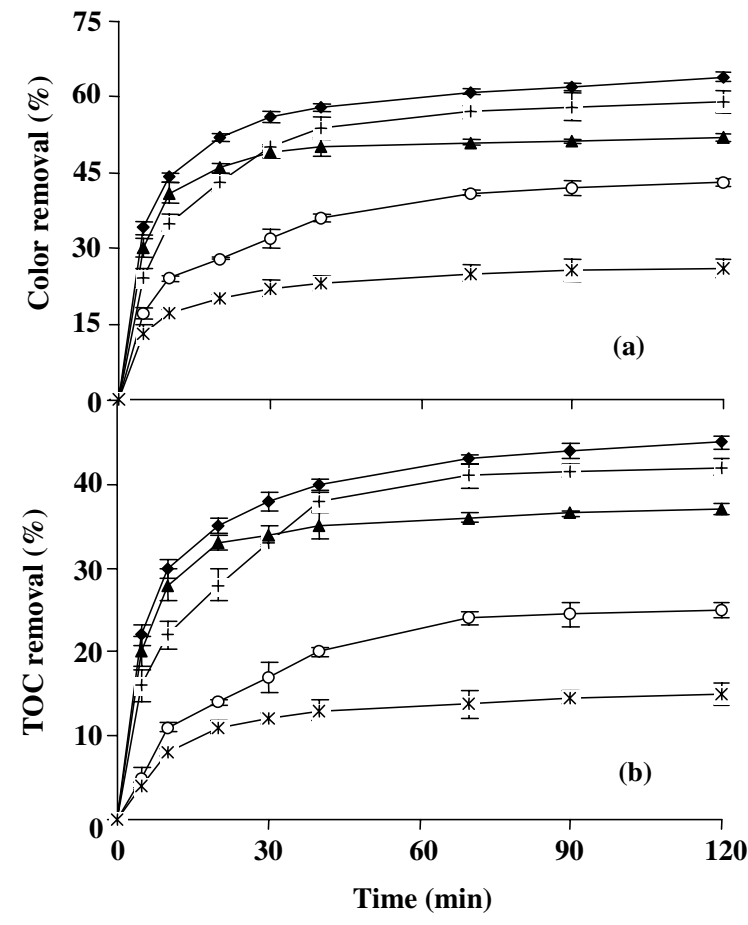

Fig. 3. Effect of four metal ions on the color (a) and TOC (b) removals of Vat Blue $\mathrm{BO}$ under the irradiation of UV light. [Vat Blue $\mathrm{BO}]=150 \mathrm{mgl}^{-1}$, [metal ions $]=5 \mathrm{mM},\left[\mathrm{H}_{2} \mathrm{O}_{2}\right]=50 \mathrm{mM}$, $\mathrm{pH}=3 .(\diamond): \mathrm{Fe}^{2+} ;(+): \mathrm{Cu}^{2+} ;(\boldsymbol{\Delta}): \mathrm{Mn}^{2+} ;(\mathrm{O}): \mathrm{Ag}^{+} ;($( $):$no metal.

\subsection{Comparison of $\mathrm{H}_{2} \mathrm{O}_{2} / \mathrm{UV}, \mathrm{H}_{2} \mathrm{O}_{2} / \mathrm{Fe}^{2+}$ and $\mathrm{H}_{2} \mathrm{O}_{2} /$ $\mathrm{Fe}^{2+} / \mathrm{UV}$ processes}

In order to compare the efficiency of the advanced oxidation processes on the degradation of Vat Blue $\mathrm{BO}$, the following advanced oxidation processes were carried out, namely $\mathrm{H}_{2} \mathrm{O}_{2} / \mathrm{UV}, \mathrm{Fe}^{2+} / \mathrm{H}_{2} \mathrm{O}_{2}$ and $\mathrm{Fe}^{2+} /$ $\mathrm{H}_{2} \mathrm{O}_{2} / \mathrm{UV}$. The results of the color and TOC removals are shown in Fig. 4. The color and TOC removals of Vat Blue BO were lower by $\mathrm{Fe}^{2+} / \mathrm{H}_{2} \mathrm{O}_{2}$ or $\mathrm{H}_{2} \mathrm{O}_{2} / \mathrm{UV}$ processes alone than by $\mathrm{Fe}^{2+} / \mathrm{H}_{2} \mathrm{O}_{2} / \mathrm{UV}$. For a reaction time of $120 \mathrm{~min}$, color and TOC removals were obtained as the followings: $\mathrm{Fe}^{2+} / \mathrm{H}_{2} \mathrm{O}_{2} / \mathrm{UV}: 64 \%$ and $45 \% ; \mathrm{Fe}^{2+} /$ $\mathrm{H}_{2} \mathrm{O}_{2}: 30 \%$ and $21 \% ; \mathrm{H}_{2} \mathrm{O}_{2} / \mathrm{UV}: 26 \%$ and $15 \%$, respectively. The degradation rate of Vat Blue $\mathrm{BO}$ by $\mathrm{Fe}^{2+} /$ $\mathrm{H}_{2} \mathrm{O}_{2} / \mathrm{UV}$ was also faster than by $\mathrm{Fe}^{2+} / \mathrm{H}_{2} \mathrm{O}_{2}$ or $\mathrm{H}_{2} \mathrm{O}_{2} /$ $\mathrm{UV}$ processes. The rapid degradation is related to the enhanced decomposition of $\mathrm{H}_{2} \mathrm{O}_{2}$ to powerful oxidizing 'OH under photo-Fenton conditions. The degradation rate of organic compounds can be strongly accelerated by irradiation with ultraviolet light (Ruppert and Bauer, 1993; Fukushima et al., 2000). The increased efficiency of the photo-Fenton is attributable to the photo-reduction of the $\mathrm{Fe}^{3+}$ formed during the Fenton process.

$\mathrm{Fe}^{3+}+h v+\mathrm{H}_{2} \mathrm{O}_{2} \rightarrow \mathrm{Fe}^{2+}+\mathrm{H}^{+}+\cdot \mathrm{OH}$

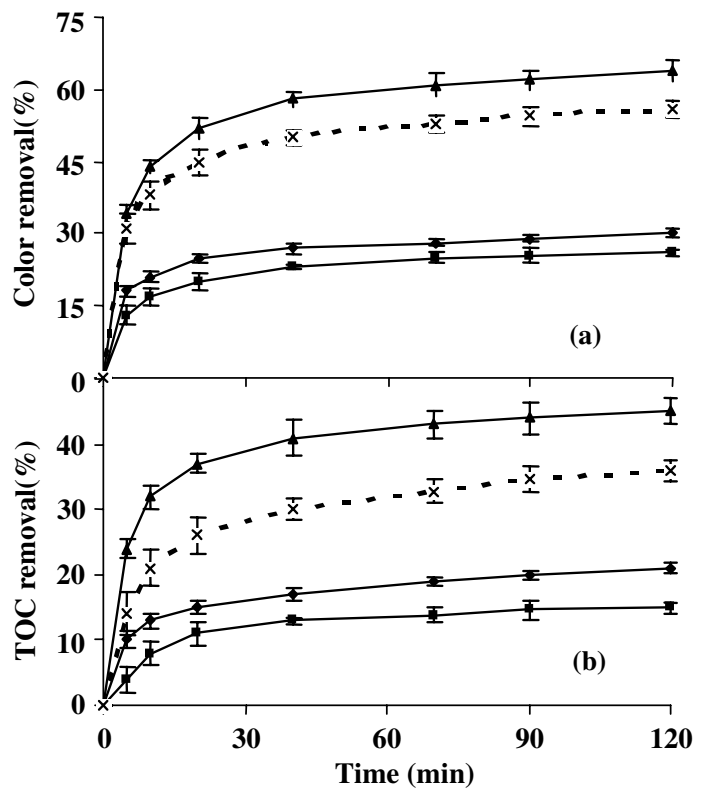

Fig. 4. The color (a) and TOC (b) removals of Vat Blue BO in three homogeneous systems. [Vat Blue $\mathrm{BO}]=150 \mathrm{mgl}^{-1}$, $\left[\mathrm{Fe}^{2+}\right]=5 \mathrm{mM},\left[\mathrm{H}_{2} \mathrm{O}_{2}\right]=50 \mathrm{mM}, \mathrm{pH}=3 .(\diamond): \mathrm{Fe}^{2+} / \mathrm{H}_{2} \mathrm{O}_{2} ;(\mathbf{\square})$ : $\mathrm{H}_{2} \mathrm{O}_{2} / \mathrm{UV} ;(\boldsymbol{\Delta}): \mathrm{Fe}^{2+} / \mathrm{H}_{2} \mathrm{O}_{2} / \mathrm{UV} ;(\times): \mathrm{Fe}^{2+} / \mathrm{H}_{2} \mathrm{O}_{2}+\mathrm{H}_{2} \mathrm{O}_{2} / \mathrm{UV}$.

During photo-reduction, an additional ${ }^{\circ} \mathrm{OH}$ is generated and the reproduced $\mathrm{Fe}^{2+}$ react with $\mathrm{H}_{2} \mathrm{O}_{2}$ to produce $\mathrm{Fe}^{3+}$ and $\mathrm{OH}$ so that the cyclic reaction can continue.

The higher efficiency observed with the $\mathrm{Fe}^{2+} / \mathrm{H}_{2} \mathrm{O}_{2} /$ UV process for the degradation of Vat Blue $\mathrm{BO}$ can be explained by the fact that $\mathrm{OH}$ radicals are generated by multiple reactions: photolysis of $\mathrm{H}_{2} \mathrm{O}_{2}$, reaction of $\mathrm{H}_{2} \mathrm{O}_{2}$ with $\mathrm{Fe}$ (II) which leads to a generation of $\mathrm{Fe}(\mathrm{III})$ and photolysis of $\mathrm{Fe}(\mathrm{III})$. The contribution of each of these reactions to the production of $\mathrm{OH}$ depends on the relative concentrations of $\mathrm{Fe}(\mathrm{II})$ and $\mathrm{H}_{2} \mathrm{O}_{2}$.

Furthermore, it is necessary to point out that the color and TOC removals by $\mathrm{Fe}^{2+} / \mathrm{H}_{2} \mathrm{O}_{2} / \mathrm{UV}$ were higher than the arithmetic sum of those by $\mathrm{Fe}^{2+} / \mathrm{H}_{2} \mathrm{O}_{2}$ and $\mathrm{H}_{2} \mathrm{O}_{2} / \mathrm{UV}$ indicating the synergistic effect of $\mathrm{UV}$ and $\mathrm{Fe}^{2+}$ on the degradation reaction.

\section{Conclusions}

Degradation of 20 dyes in aqueous solutions by the Fenton process was performed. These dyes include 6 types: acidic, reactive, direct, cationic, disperse and vat dyes. The former four types of dyes were decolorized and their TOC values were decreased significantly, while the color and TOC removals of the latter two types were lower. The catalytic abilities of four metal ions in the dark and under UV light irradiation were in the 
sequence of $\mathrm{Fe}^{2+} / \mathrm{UV}>\mathrm{Cu}^{2+} / \mathrm{UV}>\mathrm{Mn}^{2+} / \mathrm{UV}>\mathrm{Ag}^{+} /$ $\mathrm{UV}>\mathrm{Fe}^{2+}>\mathrm{Cu}^{2+}>\mathrm{Mn}^{2+}>\mathrm{Ag}^{+}$. The color and TOC removals of dye solution by $\mathrm{Fe}^{2+} / \mathrm{H}_{2} \mathrm{O}_{2} / \mathrm{UV}$ were higher than by $\mathrm{Fe}^{2+} / \mathrm{H}_{2} \mathrm{O}_{2}$ or $\mathrm{H}_{2} \mathrm{O}_{2} / \mathrm{UV}$ processes and greater than the arithmetic sum of the latter two, suggesting the synergistic effect of $\mathrm{UV}$ and $\mathrm{Fe}^{2+}$ on the degradation reaction. The Fenton process could be used to enhance biotreatment of the dye wastewater in the sewage treatment plant.

\section{References}

Benitez, F.J., Acero, J.L., Real, F.J., Rubio, F.J., Leal, A.I., 2001. The role of hydroxyl radicals for the decomposition of p-hydroxy phenylacetic acid in aqueous solutions. Water Res. 35, 1338-1343.

Bossmann, S.H., Oliveros, E., Göb, S., Siegwart, S., Dahlen, E.P., Payawan, L., Straub, M., Wörner, M., Braun, A.M., 1998. New evidence against hydroxyl radicals as reactive intermediates in the thermal and photochemically enhanced Fenton reactions. J. Phys. Chem. A 102, 5542-5550.

Chang, D.J., Chen, I.P., Chen, M.T., Lin, S.S., 2003. Wet air oxidation of a reactive dye solution using $\mathrm{CoAlPO}_{4}-5$ and $\mathrm{CeO}_{2}$ catalysts. Chemosphere 52, 943-949.

Chen, R., Pignatello, J.J., 1997. Role of quinone intermediates as electron shuttles in Fenton and photo-assisted Fenton oxidations of aromatic compounds. Environ. Sci. Technol. 31, 2399-2406.

Feng, J.Y., Hu, X.J., Yue, P.L., Zhu, H.Y., Lu, G.Q., 2003. Degradation of azo-dye Orange II by a photoassisted Fenton reaction using a novel composite of iron oxide and silicate nanoparticles as a catalyst. Ind. Eng. Chem. Res. 42, 2058-2066.

Fukushima, M., Tatsumi, K., Morimoto, K., 2000. The fate of aniline after a photo-Fenton reaction in an aqueous system containing iron(III), humic acid, and hydrogen peroxide. Environ. Sci. Technol. 34, 2006-2013.
Huang, M.H., Shih, Y.P., Liu, S.M., 2002. Biodegradation of polyvinyl alcohol by Phanerochaete chrysosporium after pretreatment with Fenton's reagent. J. Environ. Sci. Heal. A 37, 2941.

Kang, S.F., Liao, C.H., Chen, M.C., 2002. Pre-oxidation and coagulation of textile wastewater by the Fenton process. Chemosphere 46, 923-928.

Kang, S.F., Liao, C.H., Hung, H.P., 1999. Peroxidation treatment of dye manufacturing wastewater in the presence of ultraviolet light and ferrous ions. J. Hazard. Mater. B 65, 317-333.

Kurbus, T., Majcen Le Marechal, A., Voncina, D.B., 2003. Comparison of $\mathrm{H}_{2} \mathrm{O}_{2} / \mathrm{UV}, \mathrm{H}_{2} \mathrm{O}_{2} / \mathrm{O}_{3}$ and $\mathrm{H}_{2} \mathrm{O}_{2} / \mathrm{Fe}^{2+}$ processes for the decolorisation of vinylsulphone reactive dyes. Dyes Pigments 58, 245-252.

Ruppert, G., Bauer, R., 1993. The photo-Fenton reaction-an effective photochemical wastewater treatment process. J. Photochem. Photobiol. A: Chem. 73, 75-78.

Slokar, Y.M., Majcen Le Marechal, A., 1998. Methods of decolorization of textile wastewaters. Dyes Pigments 37, 335-356.

Spacek, W., Bauer, R., Heisler, G., 1995. Heterogeneous and homogeneous wastewater treatment-comparison between photodegradation with $\mathrm{TiO}_{2}$ and the photo-Fenton reaction. Chemosphere 30, 477-484.

Spadaro, J.T., Isabelle, L., Renganathan, V., 1994. Hydroxyl radical mediated degradation of azo dyes: evidence for benzene generation. Environ. Sci. Technol. 28, 13891393.

Swaminathan, K., Sandhya, S., Sophia, A.C., Pachhade, K., Subrahmanyam, Y.V., 2003. Decolorization and degradation of $\mathrm{H}$-acid and other dyes using ferrous-hydrogen peroxide system. Chemosphere 50, 619-625.

Walling, C., 1975. Fenton reagent: V. Hydroxylation and sidechain cleavage of aromatics. Accounts of Chem. Res. 8, $125-131$.

Xu, X.R., Wang, W.H., Li, H.B., 1999. Determination of hydroxyl radical in Fenton reaction by colorimetric assay and its application. Prog. Biochem. Biophys. 26, 67-69. 